\title{
IMPACT OF INDIVIDUALISM, COLLECTIVISM, MOOD, PROXIMITY AND SAVINGS ON IMPULSE BUYING BEHAVIOR IN PAKISTAN
}

\author{
SAIRA ASHFAQ \\ Bahria University, Islamabad, Pakistan \\ DR. AYUB SIDDIQUI \\ FAST National University, Islamabad, Pakistan \\ M. JAN KHAN \\ Pakistan Air Force, Pakistan
}

\begin{abstract}
The present study focuses on finding out the main attributes that determine the reasons of impulse buying behavior in Pakistan. The data has been gathered through questionnaires from 400 buyers of different cities of Pakistan, like Rawalpindi, Islamabad, Karachi, and Sargodha. The current study focuses on identifying people, who can be classified as "impulsive buyers", and "non-impulsive buyers. Despite the classifications of impulsive and non- impulsive buyers, it also identifies the level of impulsiveness in reference to purchasing, varied from time to time for both the impulsive buyers and non-impulsive buyers. After reviewing the literature, five variables have been taken for the study to determine the dependent variable. Results were analyzed using ordinary least square (OLS) regression and correlation techniques, and data has been tested which appeared significant statistically. The results indicate that impulsive buying behavior is positively associated with the collectivism, proximity and $\operatorname{mood}$ and have negative association with savings and collectivism. Further analysis can be done on the more independent variables, such as product specific impulse buying tendency.
\end{abstract}

\section{INTRODUCTION}

"Definition of impulsive buying is an unintentional (unplanned) purchase", (Cobb \& Hoyer, 1986). According the Kollat and Willett (1967) impulsive buying is an unplanned purchased. Impulse buying is an immediate purchase having no prior plan or purpose to buy the product (Beatty \& Ferrell, 1998). Consumer does impulsive buying when he/she feels vigorous enthusiasm which turns into a want to buy that product immediately (Rook, 1987).

Impulsive buying is an unplanned shopping by the buyers. There is a substantial amount of research conducted on impulsive buying behavior in developed countries. Developing countries have got less concentration on this subject. Some research is conducted on this issue, but not sufficient to determine the actual factors that actually affect the impulsive buying behavior in Pakistan.

Mood is one of the most important factors which affect the buyers because people of Asian countries are more emotional than Europeans. Saving is also having a significant value because Pakistan is a developing country, so the people give most worth to money rather than shopping. Most of the people prefer to save money rather than to use it for unplanned shopping. After studying literature on these variables, it is found that existing research on factors determining the impulsive buying are not enough to explore the actual determinants.

There is a substantial amount of research conducted on impulsive buying behavior in developed countries. In developing countries, very less concentration has been given to this research area. Some researchers studied this relationship before but findings are not sufficient to determine the actual factors that actually affect the impulse buying. Saving is one of the important factors in the Pakistani context because it is a developing country and income level is low over there so Pakistanis are very sensitive in matter of savings. Individualism and collectivism also has effect on the impulsive buying behavior. Mood and proximity have a prominent effect on the impulsive buying behavior because some people like to do impulse buying to release tension or depression 
but others like to do shopping in fresh mood. Pakistanis are very emotional people they feel greater influence of the behavior of the storekeeper. This research will find out the exact determinants of the impulsive buying behavior. After the review of the studies done in other countries, we are intending to do the study in Pakistan's perspective. The benefit of this comprehensive research is that it would be helpful in developing such strategies that would be useful to attract the impulsive buyers by the proximity factors. This research will find out actual determinants of increasing rate of impulsive buying.

\section{REVIEW OF LITERATURE}

\section{Impulsive buying}

"Definition of impulsive buying is an unintentional (unplanned) purchase", (Cobb \& Hoyer, 1986). According the Kollat and Willett (1967) impulsive buying is an unplanned purchased. Impulse buying is an immediate buy having no prior plan or purpose to buy the product (Beatty \& Ferrell, 1998). Consumer does impulsive buying when he feels vigorous enthusiasm which turns into a want to buy that product immediately (Rook, 1987).

Impulsive buying is associated with the fashion products and emotions as well (Cha, 2001; Han, Morgan, Kotsiopulos \& Kang 1991; Ko, 1993). Purchasing lifestyle explains the type of shopping either its compulsive or impulsive (Cobb \& Hoyer, 1986). Impulsive buying has weak association with consumer lifestyle, fashion involvement and post-decision stage of consumer's purchasing behavior, but there is a strong association between impulsive buying and pre- purchase decision stage. Availability of the Varity can also be a factor of impulsive buying (Tirmizi, Rehman \& Saif, 2009).

Impulsive buying is actually unplanned or unintentional shopping (Stern, 1962). Itcan provide information to other consumers about the product, so retailer can get more customers' regularity by focusing on them (Verplanken \& Sato, 2011).Impulsive buying is strongly associated with urge, behavior, personality emotions and self-control. Someone who has the ability of self-control would be less impulsive buyer as compare who has no or less (Gailliot, et. al., 2007).

Impulsive buying is associated with the self-control and personality traits (Verplanken \& Herabadi, 2001). Impulsive buying has no evaluation of alternative and no proper process it occurs just because of urge (Dholakia, Gopinath \& Bagozzi, 2005). Main reason of impulsive buying is urge, it can be reduced by repeated physical and cognitive exercises. Cognitive exercise increases the self-control (Muraven, Baumeister \& Tice 1999). When the self-control will increase by the cognitive exercises, then impulsive buying will decrease (Sultan, Joireman and Sprott, 2011). Marketers should permute the impulsive buying with association of external rewards. There are the two main aspects of the impulsive buying one is lack of urgency and second is unenthusiastic necessity (Gay, Schmidt and Linden, 2011).

Impulsive buying is a wide spread phenomena in the United States, and impulsive buying commonly exists in the lower price products like chocolates and magazines. Impulsive buying is an instantaneous and complex behavior in which the quickness of the impulse buying resolution procedure envisages considerate and purposeful deliberation of information and option selection. Impulsive buying is the unplanned purchase and most of the time they are used interchangeably (Kollat \& Wallet, 1969; Stern, 1962). Impulsive buying is the instantaneous and forceful urge of buying instantaneously (Beaty \& Farrell, 1998). Forceful urge bothers the customer to purchase immediately (Rook, 1987). Impulsive buying is the power urge to purchase which bothers the customer to purchase the product.

Level of impulsiveness varies from time to time and between the impulsive buyers and non-impulsive buyers (Vohs \& Faber, 2007). Two factors effect impulsive buying, one is desire to purchase, and second is urge to purchase. Reasons of the impulsive buying are the buying urge and desire to buy. Impulsive buying is associated with the age. Young age group is more impulsive buyers then the older people. It increases in the age of 18 to 39 and decreases after the age of the 39 (Bellenger, Robertson \& Hirshman, 1978).

There is an inverse relationship between impulsive buying and age. As the age will increase impulsive buying behavior will decrease. It's higher in the age of the 18 to 39 and decreased after the age of 39 (Wood, 1998). Impulsive buying is vary with the gender because men purchase the products on the base of rationality and finance but the women purchases base on the emotional attachment and social identity. Impulsive buying varies with the income (Dittmar, Beattie, \& Friese, 1995). Impulsive buying behavior is the gender specific (Dittmar, et. al, 1995).

\section{Mood}

There is an association between events and mood (Seligman, Kamen \& Nolen-Hoeksema, 1988). Impulsive buying is associated with emotions (Eysenck, Pearson, Easting \& Allsopp,1985). Cognition is an important component of impulsive buying (Hoch \& Loewenstein, 1991). Cognition is major component of impulsive buying and it has great impact on impulsive buying (Rook \& Fisher 1995). 
In impulsive buying individuals prefer the short term benefits or relaxation, rather than long term benefit to relax their mood (Puri, 1996). Some individuals prefer the impulsive buying to satisfy their hedonic needs but some are not interested in the rewards (Ramanathan \& Menon, 2006). Impulsive buying is associated with depression. People make impulsive buying for the removal of depression or for tension diversion (Duhachek, 2005).

Impulsive buying occurs in response of the emotional disturbance. Impulsive buying is not associated with the cognition or emotion but it is associated with stress, disappointment and depression. An individual make impulsive buying when he is depressed. Age, gender, income, or insurance coverage, hurricane victims are also the determinants of the impulsive buying (Sneath, Lacey \& Hensel, 2009). Individual make the impulsive buying for getting pleasure in the stressful life. During the impulsive buying individual forget the stress because of involvement in the shopping (Wolters, Werf \& Heuvel, 2008). Individual makes impulsive buying to hide the stressful condition and want to busy in the interesting activity which is shopping.

Mood is also having the strong association with impulsive buying. Impulsive buying is nearly associated with the pleasure, care free, and excitement. Positive mood related to the impulsive buying. Negative mood and bad mood indirectly affect the self-control. Negative mood is also associated with the impulsive buying (Herman \& Polivy, 2004). Consumer makes the purchase in the negative mood or in stress to alleviate their sad and negative mood. Pleasure mood, excitement and carefree has strong relationship with the impulsive buying (Rook \& Gardner, 1993). People make the impulsive buying in negative mood to alleviate it and to find freeway from the stress.

\section{Proximity}

Looks of the retail stores also enhances the shopping of the buyers or the customers, for example store's size, design, importance of the location and its image. Buyer get influenced by the stores physical feature of the retail stores (Eppli \& Shilling, 1996). Products' feature has a great impact on the impulsive buyers. If the product would be attractive in the looks and have attractive feature, than the customers will purchase that product impulsively. However, if the product would not be attractive then the customer will ignore that product and will not urge to buy that product. Product features create the loyalty of the customer impulsively and customer would purchase the product frequently (Jones, Reynolds, Weun \& Beatty, 2003).

Proximity Customer explained that sometime they purchase those products suddenly for which they have no prior plan. After entering the store, those products attract them so they buy. Other reasons of the impulsive buying are the setting of the shelves, design of the store and the facilitations which a retailer provides the customer. Retailer should identify those products which mostly buy impulsively. Impulsive buying is an unplanned purchased which is urged by the display of the shelves and facilities of the store. Customer buys the some product impulsively (Clover, 1950). Customers stated that they purchase some products for which they have no plan to buy before entering the store, but because of attractive setting of the store and behavior of the store keeper, it bothered us to buy those products (Cox, 1964). Impulsive buying could be enhanced by focusing on the products which are mostly purchased impulsively, design of the store, settings of the shelves and by the behavior of the store keeper (Stern, 1962). Impulsive buying is associated with the proximity factors. Proximity factors affect the impulsive buying. Proximity is also features that smooth the progress of impulsive buying. Consumer accepted that by staring the products in the retail store, or catalogues, it stimulates the urge to buy that product (Rook, 1987). Sensory inputs (touching products in the store and tasting free sample of foods) also stimulate the impulsive buying (Vohs \& Faber, 2007). Physical proximity factors also have the strong impact on the impulsive buying. These factors are the store design, free sample tasting of food; sniffing aromas also enhance the impulsive buying.

\section{Savings}

People buy the commodities impulsively because they want to give the gift them self to eradicate the depression and disappointment because they have extra money (Sneath, Lacey \& Hensel, 2009). The products which are buying impulsively mostly are not costly but are cheap in price or rate (Stern, 1962).

Money is the purchasing power which can control the others (Goldberg \& Lewis, 1978). Impulsive buyers are the status conscious and stature people (d'Astous \& Tremblay, 1989). Money is the source of worries, but also provide the relief from the depression and worries as well (Yamauchi \& Templar, 1982).

\section{Individualism}

Impulsive buying occurs when an individual want to satisfy the urge to buy immediately. For the satisfaction of the sudden buying urge, individuals make the impulsive buying instantaneously (Rook \& Fisher, 1995). Individual's choice depends on the environment and society in which individual grow. Individual is also responsible for impulsive buying (Beatty \& Ferrell, 1998). 
With the other perspective, customer is also responsible for impulsive buying contrarily. Not only the product is the cause of the impulsive buying, but the individual is also responsible for this purchase (Rook, 1987).

Recent research is focusing on the impulsive buyer and classifying them from the non-impulsive buyers because according recent research, predictor factors of impulsive buying are personal attributes rather than the product. Impulsive buying is caused by the personal attributes rather than the attributes of the product (Rook $\&$ Fisher, 1995). The causes of the impulsive buying are the personality traits of the buyers rather than the feature or the characteristic of the products. Individuals are aggravated by their own preferences, need and rights. Individuals give the priority to their own goals and emphasis on the logical and rational relationship with others (Kacen \& Lee, 2002). People are classified into two groups, one lies in the individualism and second in the collectivism. The consumer of first group (individualism) has strong relationship with the impulsive buying as compared to the second group (collectivism) (Kacen \& Lee, 2002). Impulsive buying is associated with culture. Individualism and collectivism are two main groups of the culture. The people who belong to the individualism are self-oriented, independent and autonomous. The people who belong to the second group collectivism are family oriented, more social and follow the family norms (Trandis, 1995).

\section{Collectivism}

Collectivism Impulsive buying is associated with culture. Individualism and collectivism are two main groups of the culture. The people who belong to the individualism are self-oriented, independent and autonomous. The people who belong to the second group collectivism are family oriented, more social and follow the family norms (Trandis, 1995). Impulsive buying strongly associated with the individualistic culture as compared to the collectivism culture (Gutierrez, 2004). Some people claim that they are in the collectivism but in actual they are not in the collectivism (Gutierrez, 2004).

THEORETICAL FRAMEWORK FIGURE 1

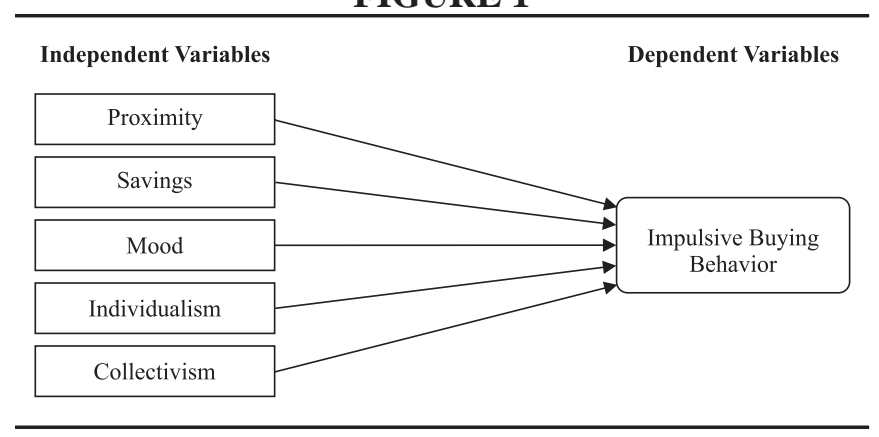

\section{METHODOLOGY}

\section{Instrumentation}

Questionnaires contained thirty four items and two sections. Section one had twenty eight items which are the research model relevant questions but section two contains six questions related to demographic of respondents.

TABLE 1

Characteristics of sample

\begin{tabular}{|c|c|c|c|}
\hline Items & Items & Frequency & Percentage \\
\hline \multirow[t]{2}{*}{ Gender } & Male & 66 & $21 \%$ \\
\hline & Female & 239 & $79 \%$ \\
\hline \multirow[t]{8}{*}{ Age } & $21 \&$ less & 70 & $22 \%$ \\
\hline & $21-25$ & 84 & $30 \%$ \\
\hline & $26-30$ & 49 & $19 \%$ \\
\hline & $31-35$ & 46 & $16 \%$ \\
\hline & $36-40$ & 20 & $8 \%$ \\
\hline & $41-45$ & 15 & $4 \%$ \\
\hline & $46-50$ & 2 & $0.7 \%$ \\
\hline & $51 \&$ above & 0 & $0 \%$ \\
\hline \multirow{3}{*}{$\begin{array}{l}\text { Shopping } \\
\text { frequency } \\
\text { per week }\end{array}$} & $\begin{array}{l}\text { Less than } 2 \\
\text { times }\end{array}$ & 75 & $13 \%$ \\
\hline & $2-5$ times & 250 & $60 \%$ \\
\hline & $\begin{array}{l}\text { More than } 5 \\
\text { times }\end{array}$ & 175 & $27 \%$ \\
\hline \multirow[t]{6}{*}{ Occupation } & Students & 2 & $0.7 \%$ \\
\hline & Business sector & 89 & $29 \%$ \\
\hline & Land lords & 78 & $26 \%$ \\
\hline & Job holders & 27 & $9 \%$ \\
\hline & Manufacturer & 85 & $28 \%$ \\
\hline & $\begin{array}{l}\text { Education } \\
\text { sector }\end{array}$ & 24 & $8 \%$ \\
\hline \multirow[t]{4}{*}{ Income } & Less than 25000 & 5 & $2 \%$ \\
\hline & $25001-35000$ & 24 & $8 \%$ \\
\hline & $35001-50,000$ & 63 & $21 \%$ \\
\hline & Above 50,000 & 213 & $69 \%$ \\
\hline \multirow[t]{4}{*}{ Qualification } & Inter & 105 & $34 \%$ \\
\hline & Undergraduate & 96 & $31 \%$ \\
\hline & Graduate & 70 & $23 \%$ \\
\hline & Post graduate & 36 & $12 \%$ \\
\hline
\end{tabular}

\section{Sample and procedure}

The population for data collection was customers of Pakistan. The sample was collected from various cities 
of Pakistan i.e. Sargodha, Lahore and Rawalpindi and the sample size is 400 customers. The questionnaires were personally administered. Total 400 questionnaires were distributed, out of which 305 questionnaires were received back, making the response rate as $76 \%$.

Data was collected from both males and females for avoidance of biased results. So, the characteristics, i.e., gender, Age, Occupation, Shopping frequency per week, qualification and income of the customers vary from customer to customer. All of the above characteristics of the respondents of sample are summarized in the table 1.

In the society of Pakistan females are more shopping lovers than males because of busy schedule of them. In this country mostly females are house wives and they have no concern with the businesses and any other activities. That's why only $21 \%$ response is gathered from the males.

\section{RESULTS}

Statistical Package for the Social Sciences (SPSS) is used for the results. Correlation analysis shows the relationship among the variables but the regression analysis shows the confidence level, significance and beta. Regression analysis also shows the model summary.

Linear association is checked by the Pearson correlation analysis between the variables in the study which is reported in table 2. Correlation statistics shows the association between the variables that how the two variables are associated with each other, it tells that if one variable moves in one direction the other variable will move in the similar direction or opposite to that. We found that the dependent variable impulsive buying behavior is having significant correlation with all the five independent variables. It has positive association with collectivism, mood and proximity but have negative or opposite association with savings and individualism. The association between the independent variables shows that they are strongly associated between themselves and all of the correlation results are significant at the level of $p<0.01$. Collinearity statistics shows that there is a chance of multicollinearity in the data but variance inflation factor (VIF) which is the test for checking multicollinearity shows that there is no such problem of multicollinearity as all the values of VIF are less than 10 and tolerance values are greater than zero. Correlation analysis indicates that there is a strong and significant relationship among the impulsive buying behavior, proximity, collectivism and mood. But, the relationship of impulsive buying behavior with individualism and saving is strongly negative.

\section{Regression Analysis}

Regression test is used to check the relationship between the dependent and independent variables. Regression results from table 3 show the significance of the regression model and its explanatory power. The regression analysis indicates that the value of $\mathrm{R}$ Square is 0.678 , which indicates that there is $67.8 \%$ variation in impulsive buying behavior is explained by the variables in the study while $32.2 \%$ variation is due to those factors, which are not considered in this model. The value of $\mathrm{F}$ is 139.787and is significant showing the fitness of the model. The results of the study showed that all the variables have significant impact on impulsive buying behavior.

Result suggests that 1 unit increase in proximity will increase the impulsive buying behavior by 0.438. Mood is also having significant impact on the impulsive buying behavior. Collectivism has positive and strong relationship with the impulse buying behavior. Regression result shows that 1 unit increase in collectivism will result an increase of 0.227 in impulsive buying behavior and the result is significant at the level of $p<0.001$. Individualism and saving have the strong but negative relationship. Results show that 1 unit change in the savings will decrease the impulsive buying behavior by .223. Individualism also have negative impact on the impulsive buying behavior with 1 unit change in it will bring a reduction of .197 in impulsive buying behavior.

TABLE 2

Correlation

\begin{tabular}{|c|c|c|c|c|c|c|}
\hline Variables & 1 & 2 & 3 & 4 & 5 & 6 \\
\hline 1. Impulsive Buying Behavior & 1 & & & & & \\
\hline 2. Proximity & $0.713 * *$ & 1 & & & & \\
\hline 3. Mood & $0.692 * *$ & $0.676^{* *}$ & 1 & & & \\
\hline 4. Individualism & $-0.700 * *$ & $0.512 * *$ & $0.571 * *$ & 1 & & \\
\hline 5. Collectivism & $0.668 * *$ & $0.517 * *$ & $0.619 * *$ & $-0.815^{* *}$ & 1 & \\
\hline 6. Savings & $-0.748 * *$ & $0.519 * *$ & $0.598 * *$ & $0.679 * *$ & $-0.711 * *$ & 1 \\
\hline
\end{tabular}

$N=305,{ }^{* * *} p<0.001,{ }^{* *} p<0.01, * p<0.05$ 
TABLE 3

Regression analysis

\begin{tabular}{|c|c|c|}
\hline \multirow[t]{2}{*}{ Predictors } & \multicolumn{2}{|c|}{ Impulsive Buying Behavior } \\
\hline & $\beta$ & $\mathbf{R}^{2}$ \\
\hline Proximity & $.438 * * *$ & \\
\hline Mood & $.321 * * *$ & \\
\hline Individualism & $-.197 * * *$ & \\
\hline Collectivism & $.227 * * *$ & \\
\hline Savings & $-.223 * * *$ & .678 \\
\hline
\end{tabular}

\section{DISCUSSION}

Pakistanis are emotional people; they get excited by the advertisement and behavior of the shopkeeper, so they start buying the products. So proximity has strong impact on impulsive buying. Retailers must promote the impulsive buying by the attractive design of the retail store and by promoting the positive points of the impulsive buying. Retailers must be conscious that no negative point of impulsive buying exists in the store. They should promote impulsive buying with any extrinsic rewards or any external rewards (Gutierrez, 2004). Pakistan is high on collectivism, so the people who prefer the family goals are more impulsive buyers because when they go with their families they cannot ignore request of them.

Mood is a very prominent determinant of the impulsive buying behavior. Buying and cognition has great impact on impulsive buying (Rook \& Fisher, 1995). In impulsive buying individual prefer the short term benefits or relaxation rather than long term benefit to relax their moods (Puri, 1996). Some individuals prefer the impulsive buying to satisfy their hedonic needs but some are not interested in the rewards (Ramanathan \& Menon, 2006). Impulsive buying is associated with depression. People make impulsive buying for the removal of depression or for tension diversion (Duhachek, 2005).

Impulsive buying is 'extensively known phenomena' in the United States. Products categories such as magazines and chocolate and apparels are usually purchased spontaneously. Impulsive buying behavior is unexpected forceful hedonically multifaceted purchasing behavior in which the quickness of the impulse purchase decision process predicts considerate purposeful thought of information and choice option. Researchers found that "individuals" are responsible for impulsive buying contrarily to previous believe that the "product" contributes impulsive buying. In view of these findings, the researchers started redefining the variable "impulsive buying". Several researchers thus conceptualized impulse buying from customers' perspective. According to these researchers impulsive buying is a sudden and powerful urge to buy immediately. The predictor variables in most of the recent researcher are "Personal attributes", as compared to previous researches in which the predictor variables were products. Thus, this research focused on identifying people, who could be classified as "impulsive buyers", and "non-impulsive buyers. Despite the classifications of impulsive and non- impulsive buyers, it also examined the level of impulsiveness in reference to purchasing, varied from time to time for both the impulsive buyers and nonimpulsive buyers.

According the results of this study in the Pakistani collectivist culture is positively associated with the impulsive buying behavior because here people live in the joint family systems, and when they go for the shopping they purchase those things which are not the part of their list. They cannot say no to the elders and children so they make impulse buying.

\section{LIMITATIONS}

There are two limitation of this study. One is that data is collected only from the Punjab province and the remaining three provinces are not a part of this study i.e. Sindh, Balochistan and Khyeber Pakhtunkhwa. Secondly, product specific impulse buying tendency also has a strong impact on the impulsive buying behavior so in the future study it will be consider. Another limitation is the ignorance of the control variables e.g. age, income, context and personality of the buyers. These limitations should be addressed by future researchers.

\section{REFERENCES}

Applebaum, William. "Studying customer behavior in retail stores." The Journal of Marketing (1951): 172-178.

Beatty, S. E., \& Ferrell, M. E. (1998). Impulse buying: modeling its precursors. Journal of Retailing, 74(2), 169-191.

Bellenger, D. N., Robertson, D. H., \& Hirschman, E. C. (1978). Impulse buying varies by product. Journal of Advertising Research, 18(6), 15-18.

Cha, J. (2001). Planning and Unplanned apparel purchase typology and related variables. unpublished thesis, Seoul National University, Seoul.

Clover, V. T. (1950). Relative importance of impulsebuying in retail stores. The Journal of Marketing, 66-70.

Cobb, C. J., \& Hoyer, W. D. (1986). Planned versus impulse purchase behavior. Journal of Retailing.

Cox, K. (1964). The responsiveness of food sales to 
shelf space changes in supermarkets. Journal of Marketing Research, 63-67.

d'Astous, A., \& Tremblay, S. (1989). The compulsive side of" normal" consumers: An empirical Study. Faculté d'administration, Université de Sherbrooke.

Dell'Osso, B., Altamura, A. C., Allen, A., Marazziti, D., \& Hollander, E. (2006). Epidemiologic and clinical updates on impulse control disorders: a critical review. European archives of psychiatry and clinical neuroscience, 256(8), 464-475.

Dholakia, U. M., Gopinath, M., \& Bagozzi, R. P. (2005). The role of desires in sequential impulsive choices. Organizational Behavior and Human Decision Processes, 98(2), 179-194.

Dittmar, H., Beattie, J., \& Friese, S. (1995). Gender identity and material symbols: Objects and decision considerations in impulse purchases. Journal of Economic Psychology, 16(3), 491-511.

Duhachek, A. (2005). Coping: A multidimensional, hierarchical framework of responses to stressful consumption episodes. Journal of Consumer Research, 32(1), 41-53.

Eppli, M. J., \& Shilling, J. D. (1996). Changing economic perspectives on the theory of retail location. In Mega trends in retail real estate (pp. 65-80). Springer Netherlands.

Eysenck, S. B., Pearson, P. R., Easting, G., \& Allsopp, J. F. (1985). Age norms for impulsiveness, venturesomeness and empathy in adults. Personality and Individual Differences, 6(5), 613619.

Gailliot, M. T., Baumeister, R. F., DeWall, C. N., Maner, J. K., Plant, E. A., Tice, D. M., \& Schmeichel, B. J. (2007). Self-control relies on glucose as a limited energy source: willpower is more than a metaphor. Journal of Personality and Social Psychology, 92(2), 325.

Gay, P., Schmidt, R. E., \& Van der Linden, M. (2011). Impulsivity and intrusive thoughts: Related manifestations of self-control difficulties?. Cognitive therapy and research, 35(4), 293-303.

Goldberg, H., \& Lewis, R. T. (2000). Money madness: The psychology of saving, spending, loving, and hating money. Wellness Institute, Inc..

Gutierrez, B. P. B. (2004). Determinants of planned and impulse buying: The case of the Philippines. Asia Pacific Management Review, 9(6), 1061-1078.

Han, Y. K., Morgan, G. A., Kotsiopulos, A., \& KangPark, J. (1991). Impulse buying behavior of apparel purchasers. Clothing and Textiles Research Journal, 9(3), 15-21.

Herman, C. P., \& Polivy, J. (2004). The self-regulation of eating: Theoretical and practical problems.

Hoch, S. J., \& Loewenstein, G. F. (1991). Time- inconsistent preferences and consumer self-control. Journal of Consumer Research, 492-507.

Jones, M. A., Reynolds, K. E., Weun, S., \& Beatty, S. E. (2003). The product-specific nature of impulse buying tendency. Journal of Business Research, 56(7), 505-511.

Kacen, J. J., \& Lee, J. A. (2002). The influence of culture on consumer impulsive buying behavior. Journal of Consumer Psychology, 12(2), 163-176.

Ko, S. (1993). The study of impulse buying of clothing products. Unpublished Master's Thesis, Seoul National University, Seoul.

Kollat, D. T., \& Ronald, P. Wallet, 1969."Is Impulsive Purchasing Really a Useful For Marketing Decisions”. Journal of Marketing, 33, 79-83.

Muraven, M., Baumeister, R. F., \& Tice, D. M. (1999). Longitudinal improvement of self-regulation through practice: Building self-control strength through repeated exercise. The Journal of Social Psychology, 139(4), 446-457.

Puri, R. (1996). Measuring and modifying consumer impulsiveness: A cost-benefit accessibility framework. Journal of Consumer Psychology, 5(2), 87-113.

Ramanathan, S., \& Menon, G. (2006). Time-varying effects of chronic hedonic goals on impulsive behavior. Journal of Marketing Research, 43(4), 628-641.

Rook, D. W. (1987). The buying impulse. Journal of consumer research, 189-199.

Rook, D. W., \& Fisher, R. J. (1995). Normative influences on impulsive buying behavior. Journal of Consumer Research, 305-313.

Rook, D. W., \& Gardner, M. P. (1993). In the mood: impulse buying's affective antecedents. Research in Consumer Behavior, 6(7), 1-28.

Seligman, M. E., Kamen, L. P., \& Nolen-Hoeksema, S. (1988). Explanatory style across the life span: achievement and health. Child Development in Life-Span Perspective, 91-114.

Sneath, J. Z., Lacey, R., \& Kennett-Hensel, P. A. (2009). Coping with a natural disaster: Losses, emotions, and impulsive and compulsive buying. Marketing Letters, 20(1), 45-60.

Stern, H. (1962). The significance of impulse buying today. The Journal of Marketing, 59-62.

Sultan, A. J., Joireman, J., \& Sprott, D. E. (2012). Building consumer self-control: The effect of self-control exercises on impulse buying urges. Marketing Letters, 23(1), 61-72.

Tirmizi, M. A., Rehman, K. U., \& Saif, M. I. (2009). An empirical study of consumer impulse buying behavior in local markets. European Journal of Scientific Research, 28(4), 522-532.

Triandis, H. C. (1995). Individualism \& collectivism. 
Westview press.

Verplanken, B., \& Herabadi, A. (2001). Individual differences in impulse buying tendency: Feeling and no thinking. European Journal of Personality, 15(S1), S71-S83.

Vohs, K. D., \& Faber, R. J. (2007). Spent resources: Selfregulatory resource availability affects impulse buying. Journal of Consumer Research, 33(4), 537-547.

Wolters, E. C., van der Werf, Y. D., \& van den Heuvel,
O. A. (2008). Parkinson's disease-related disorders in the impulsive-compulsive spectrum. Journal of Neurology, 255(5), 48-56.

Wood, M. (1998). Socio-economic status, delay of gratification, and impulse buying. Journal of Economic Psychology, 19(3), 295-320.

Yamauchi, K. T., \& Templer, D. J. (1982). The development of a money attitude scale. Journal of Personality Assessment, 46(5), 522-528. 